\title{
A CONCEPÇÃO DE VAZIO EM ROLAND BARTHES
}

\author{
The CONCEPTION OF EMPTINESS IN ROLAND BARTHES
}

\author{
Rodrigo Fontanari \\ Universidade de Sorocaba \\ Sorocaba, SP - Brasil \\ ORCID 0000-0001-8580-3029
}

\section{Resumo}

Este ensaio busca reler $O$ Império dos signos, em que Barthes elabora, à sua maneira, uma espécie de etnografia da cultura oriental, especialmente a arte de vida japonesa, que será para ele como a revelaçáo de uma estética muito pessoal, que ele parece ter intuído desde $O$ Grau zero da escritura: a estética do vazio. Essa estética encontra, por hipótese, conclusão sob o nome de Neutro, essa utopia da linguagem que suspende toda a significação. A meio caminho entre $O$ Grau zero da escritura e $O$ Neutro, $O$ Império dos signos será o pivô desta pesquisa.

Palavras-chave: vazio; grau zero; neutro; romance utópico; Roland Barthes.

\begin{abstract}
This essay aims to reread The Empire of Signs, in which Barthes develops, in his own way, a kind of ethnography of Eastern culture, especially the art of Japanese life. This which, for him, was a revelation of a highly personal aesthetics, which he seems to have intuited since Writing Degree Zero: the aesthetics of emptiness. This aesthetics presumably found a conclusion in The Neutral, that utopia of language that suspends all signification. Halfway between Writing Degree Zero and The Neutral, The Empire of Signs will be the focus of this research.
\end{abstract}

Keywords: emptiness; degree zero; neutral; utopian novel; Roland Barthes.

\section{Résumé}

Cet essai recherche relire L'Empire des signes, Roland Barthes y élabore, à sa manière, une sorte d'ethnographie de la culture orientale, notamment de l'art de vivre japonais, qui est pour lui comme la révélation d'une esthétique bien personnelle dont il semble avoir eu l'intuition lors de la préparation de Le Degré zéro de l'écriture: l'esthétique $d u$ vide. Cette esthétique trouve, par hypothèse, son achèvement sous l'appellation de Neutre, cette utopie du langage qui suspend toute la signification sans, néanmoins, avoir raison de l'appel du sens. A mi-chemin entre Le degré zéro de l'écriture et Le Neutre, L'Empire des signes constituera donc le pivot de cette recherche.

Mots-clés: vide; degré zéro; neutre; romance utopique; Roland Barthes. 


\section{Do Grau zero ao Império dos signos}

Começo por citar um grande poeta que, embora ausente do cânone literário de Barthes, formulou uma crítica ao poder sugestivo das palavras e ao murmúrio das artes proverbiais que parece feita para reapresentar o "grau zero" e sua prerrogativa de silêncio. "O mundo mudo é nossa única pátria”, escreveu Francis Ponge (PONGE, 1961, p. 199), em seu perturbador livro Méthodes, designando à poesia aquela mesma destruição da linguagem prevista nas escrituras barthesianas ditas "brancas" ou "neutras" que, de certa maneira, aludem a uma espécie de esvaziamento do signo. Na época da escrita de $O$ Grau zero da escritura, em 1953, o termo "vazio" ainda não havia de fato conquistado a glosa de Barthes.

Atente-se para o que estes termos "branco" e "neutro", reivindicados à escritura, em 1953 já anunciavam sobre a linguagem. De par com a palavra escritura, o branco ou o neutro marcam a libertação "de toda servidão a uma ordem marcada da linguagem" (BARTHES, OC, I, 2002, p. 65)1, estabelecendo uma "escritura amodal" em que não ocorre o desenvolvimento de "formas optativas ou imperativas (quer dizer, patéticas)” (BARTHES, OC, I, 2002, p. 217).

Ora, não consiste numa escritura impassível, mas antes numa escritura inocente, cuja forma não implica nenhuma espécie de "refúgio, de 'segredo', ou ainda sem "qualquer recurso à elegância ou à ornamentação” (BARTHES, OC, I, 2002, p. 218). Trata-se de um combate ao caráter reificado das palavras e de restaurar as coisas do mundo ao seu estado de "grau zero" ao dissolver as camadas de metáforas que encobrem a qualidade diferencial dos objetos.

Devolve-se assim ao mundo o lugar que os escritores lhe roubaram, ao colorem as palavras no lugar das coisas. Desembaraçada de jogos metafóricos, de um coração romântico, a escritura produz momentos que parecem entregar os objetos em sua primeira aparição; no ponto mesmo de sua incidência, ou para dizer com Barthes, "aproxima-se de um ato breve, singular, cuja opacidade afirma a solidão,

1 As citações da obra de Roland Barthes são, aqui, feitas, salvo menção contrária, a partir das Oeuvres Complètes, estabelecidas, organizadas e apresentadas por Éric Marty em 5 tomos, em 2002. Doravante, a referência virá na forma abreviada OC seguida do tomo à que se refere em número romano. 
portanto uma inocência” (BARTHES, OC, I, 2002, p. 217). E o incidente, como se sabe, é objeto de toda uma reflexáo de $O$ Império dos signos, livro em torno do qual se pretende desenvolver este ensaio sobre a noção de vazio.

Se há um elemento que une $O$ Grau zero da escritura e $O$ Império dos signos é a realização da "ética do signo" suscitada pela "responsabilidade da forma". E, mais do que construir a ponte de $O$ grau zero da escritura ao Império dos signos, a "ética do signo" estabelece uma linha do "possível" que nunca é ultrapassada e a que Barthes se mantém fiel até a sua obsessão final, o romance ${ }^{2}$ que não se escreve, Vita Nova . Essa "linha do possível" é o estado de "moderação" que marca a noção de Neutro. Explico-me.

Desde as páginas de seu livro de estreia, Barthes sonha com um mundo em que a linguagem não seria mais uma alienação, ao contrário, pela conscientização da "moral da forma" ou da necessidade da busca pelo "frescor da linguagem" (BARTHES, OC, IV, 2002, p. 666). O escritor entra, então, em combate com sua linguagem, para desmascarar "o monstro" - como ele nomeia -, que se esconde atrás dos signos. Enquanto em $O$ Império dos signos, o semiólogo se depara com um mundo em que o sentido náo pode mais se fixar; o signo torna-se uma miragem, uma ficção, e não mais um inimigo que deve ser combatido. Tem razão Bernard Comment em Roland Barthes vers le Neutre, ao dizer que o Oriente fissura o simbólico barthesiano pela "fiç̧ão de um Neutro" (COMMENT, 2002, p. 68).

Apresente-se o volume. Por encomenda da editora Skira, O Império dos signos, como testemunha mais recente da biógrafa de Roland Barthes, Thyphaine Samoyault, reúne um conjunto de "notas redigidas no curso de três viagens sucessivas que ele fez a este

2 Entende-se, neste caso, o termo romance por romanesco sem o romance, nos termos mesmos de Barthes "[...] o que é contado, não é uma aventura, são incidentes: é preciso tomar a palavra num sentido bem esguio, táo pudico quanto possível. $\mathrm{O}$ incidente, já bem menos forte que acidente (mas talvez mais inquietante) é simplesmente o que cai vagarosamente, como um afolha, sobre o tapete da vida: é esta dobra leve, trazido ao tecido dos dias; é o que pode ser apenas notado: uma espécie de grau zero da notaçáo, justo o que é necessário para poder escrever alguma coisa [...] tudo pleno cuja espera parece o oco" (BARTHES, OC, V, 2002, p. 109)

3 Sobre este assunto, recomenda-se a pesquisa de fôlego de Claudia Amigo Pino (2015) em Roland Barthes: a aventura do romance. 
país" (SAMOYAUT, 2015, p. 427) ${ }^{4}$ a convite do amigo e diretor do Instituto Franco-Japonês, Maurice Pinguet ${ }^{5}$, a quem aliás Barthes dedica a obra. São as notaçóes feitas em seu caderno de compromissos, durante essa primeira viagem, de 2 de maio a 2 de junho de 1966, que fornecem "[...] todo o material de base que as viagens seguintes apenas fazem afirmar ou confirmar” (SAMOYAUT, 2015, p. 427).

Pura "excitação do olhar crítico" (CALVET, 1990, p. 139). É essa "excitação" que se depreende dos 26 breves e fulgurantes fragmentos que renderam a Barthes essas suas notas, e que refletem certos aspectos da cultura japonesa.

Não se trata aí, como possa parecer, de um livro de impressóes de viagem. É um Japão inteiramente imaginado e refratado pelo jogo da anamnese que se dá a ver. Tanto é que Barthes mesmo começa por confessar: o "Oriente me é indiferente". E, algumas linhas mais adiante, ele assume ainda, transformando a primeira pessoa do singular em terceira, que "em nenhum sentido fotografou o Japão" (BARTHES, OC, III, 2002, p. 352). Ao buscar conservar a inocência de um primeiro olhar, o que se lê em $O$ Império dos signos é a acuidade etnográfica de observação, que capta "[...] um certo número de traços (palavra gráfica e linguística) e com esses traços formar deliberadamente um sistema" (BARTHES, OC, III, 2002, p. 351). Tudo isso traduzido numa escrita detalhada e delineada, convida o leitor a entrar "num sistema denominado Japão" (BARTHES, OC, III, 2002, p. 351) pela forma das pálpebras, pela arte dos pacotes, pelo uso dos palitos, pela arte do gesto gráfico desenhando ou escrevendo o endereço, pela inclinação de uma saudação.

Em O Império dos signos, Barthes não transforma, por meio de uma escrita eufórica, o Japão ou seu Japão num objeto crítico analítico, como aliás observou um dos mais expressivos teóricos da desconstrução, Jonathan Culler, em As ideias de Roland Barthes, e sim num recenseamento dos objetos e das práticas da vida cotidiana, cujas "formas são esvaziadas de sentido e tudo é superfície" (CULLER,

4 As outras duas viagens também à capital do Japáo, Tóquio, ocorrem nos dois anos seguintes, em 1967 e 1968.

5 O crítico desempenhou um papel importante no interesse despertado pelo Japão no mundo intelectual francês. Ele passou boa parte de sua vida no Japão como professor na Universidade de Tóquio ou como diretor do Institut franco-japonais. (BARTHES, 2015). 
1988, p. 94), "exprimindo assim, aos meus olhos, a utopia do mundo estritamente semântica e ao mesmo tempo estritamente ateu” (BARTHES, OC, III, 2002, p. 667).

Transformando o Japão num texto, Barthes chama a atenção para forma de sua escritura, que "em suma e à sua maneira" corresponde a um acontecimento zen, a uma espécie de satori: "um abalo sísmico mais ou menos forte (não solene) que faz vacilar o conhecimento" (BARTHES, OC, III, 2002, p. 354). Cabe explicitar ainda a respeito de experiência zen do satori, cuja acepção a esse termo a cultura ocidental bloqueia. É uma experiência em que a linguagem malogra, "não diz respeito à linguagem, portanto à definição, diz algum respeito à descrição [...] intraduzível” (BARTHES, 2002, p. 219), apressa-se a explicar Barthes.

Intraduzível pois não consiste num efeito de linguagem, mas de "[...] impressão, que remete, ocidentalmente, a concepçôes de linguagem cristâs: conversão, iluminação" (BARTHES, 2002, p. 220). O satori, no entanto, não tem nada a ver com a "descida de uma verdade, de um deus, mas sim súbito desembocar no vazio" (BARTHES, 2002, p. 220). Ele dissipa a dúvida, porém não em detrimento de uma certeza. Ilumina (insight), sem clarear. Não mata o sentido, nem tão pouco o embaralha; o satori Zen destrama a linguagem, não a deixando se aprisionar no sistema paradigmático estrutural, se esquivando ardentemente de qualquer conflito, por desaguá-la numa espécie de sistema de deslizamento contínuo.

"Vazio de fala", o vacilo do sentido

Afinal, o que revela o Japão para Barthes? Penso, de saída, em uma resposta: o "vazio de fala" (BARTHES, OC, III, 2002, p. 352). Essa resposta certamente não surpreende os leitores de Barthes que, em algum momento, já notaram que $O$ Império dos signos é o livro barthesiano em que há maior ocorrência do termo vazio. Tão pouco ainda tal expressáo causa estranhamento naqueles leitores que já notaram em Roland Barthes por Roland Barthes a entrada "vejo a linguagem”, em que o semiólogo assume uma certa scopia da linguagem, isto é, "ver o que escuto"(BARTHES, OC, IV, 2002, p. 735). 
"O Japão o iluminou com múltiplos clarôes" (BARTHES, OC, III, 2002, p. 352), como ele prefere dizer, e o fez entrar não na procura do "tempo perdido" - ele o fará à sua maneira alguns anos mais tarde em $A$ Câmara clara -, mas do signo cujo aceno breve de sentido provoca "uma reviravolta", "[...] uma sacudida do sentido, dilacerado, extenuado até o vazio insubstituível, sem que o objeto cesse jamais de ser significante" (BARTHES, OC, III, 2002, p. 354). Sacudida essa que é capaz de operar um vazio de fala. E é "[...] desse vazio que partem os traços com que o Zen, na isenção de todo sentido, escreve os jardins, os gestos, as casas, os buquês, os rostos, a violência" (BARTHES, OC, III, 2002, p. 354).

Estrangeiro numa língua estranha, Barthes, no entanto, não se sente excluído e se entrega ao puro deleite do signo. O Oriente é o antídoto ao fascismo da língua, na medida em que aí "essa diabrura, a linguagem" se revela nas "formas de seu vazio - que é o contrário absoluto de seu oco" (BARTHES, OC, IV, 2002, p. 441). A opacidade quase plena da língua japonesa coloca Barthes numa dupla condição: ou regressa à incomunicação, em que o sujeito é incapaz de tirar uma linha de sentido (não sentido), ou entáo se entrega a uma outra via, a uma espécie de "revolta semiológica", que se atenta um sentido velado, místico, para aquém da linguagem, que não é senão uma escuta flutuante do significante, a "significância pura" ${ }^{\circ}$, em que se percebe e recebe sentido (e o sentido) sem, no entanto, que ele seja remetido a um significado último. Como se sabe, Barthes náo se tornou incomunicável; ao contrário, ele aí se mostrou inteiramente em comunicação com o Japão através dos gestos, dos movimentos, dos ritmos, captando dessa língua inteiramente desconhecida "a respiração, a aeração emotiva” (BARTHES, OC, V, 2002, p. 355). Ou ainda, para usar uma expressão de Barthes mesmo, ele se póe a escutar o "rumor" da língua.

6 Esse termo é empregado na acepção que lhe atribui Julia Kristeva, para quem a significância designa algo da vaga atmosfera de sentidos em que o ser humano vive imerso ainda no estado embrionário. Os traços desses sentidos são pulsionais e não se encontram ainda articulados com os signos. Em outros termos, uma forma de expressão ainda não está amarrada a um significado. Desse tempo de antanho, o sujeito não há nenhuma preservação de significados, apenas uma nostalgia da maneira pela qual as pulsôes agem nas relações originárias de mediação do corpo com o mundo. Desse ponto de vista, a significância remete à nossa imaginação e nos faz vivenciar a ilusão de resgatar espectro da ordem do imemorável. (KRISTEVA, 1974) 
Ao captar as coisas como acontecimento, como um incidente, a significância abre a linguagem a uma "comunicação silenciosa" e imediata (que é a "plenitude da linguagem"). Acede-se, assim, a um "estado de a-linguagem", em que é a densidade do significado que é atacado, noutras palavras, "[...] a raiz do sentido, para fazer com que esse sentido não se difunda, não se interiorize, não se torne implícito, não se solte, não divague no infinito das metáforas, nas esferas do símbolo" (BARTHES, OC, III, 2002, p. 408).

Distanciado completamente de toda e qualquer imposiçáo do ocidental do código, tudo aí parece entrar numa suspensão de sentido. Essa "suspensão de sentido" não se refere a um impedimento de compreender, uma vez que, nesse caso, náo corresponde, como possa imaginar, à busca por uma condiçáo anterior ao sentido, mas à procura por uma condição além do sentido (um après-sens). Não é também uma recusa total ao sentido.

A noção de sentido é posta num deslizamento progressivo: "Há sentido [não um único sentido], mas esse sentido não se deixa 'pegar'” (BARTHES, OC, IV, 2002, p. 674). Isso tudo equivale ao que Barthes mesmo escreve a respeito do corredor Shikidai:

Incentrado, o espaço é também reversível: podemos virar ao contrário o corredor de Shikidai e nada acontecerá, senão uma inversão sem consequência do alto e do baixo, da direita e da esquerda: o conteúdo é despedido sem volta: quer passemos, atravessemos ou nos sentemos diretamente no assoalho (ou no teto, se viramos a imagem), não há nada para agarrar (BARTHES, OC, III, 2002, p. 433-437).

São nestes termos que Barthes prossegue no fragmento a "Isenção de sentido", já evocado: "[...] devemos percorrer, como se passássemos por toda a extensão de um caminho iniciático, todo o sentido, de modo a poder extenuá-lo, isentá-lo" (BARTHES, OC, IV, 2002, p. 387). Aliás, deslizar de um sentido ao outro é para Barthes entrar na "infinitude da linguagem".

A construçáo sígnica do Oriente (lavada de sua expressividade) faz com que esse signo valha pelo "gesto da ideia", pelo traço, e não pela significação. É o signo despossuído de sua intencionalidade, 
sem o peso do sujeito psico e lógico do Ocidente. Extremamente delicados, os signos japoneses são signos e apenas signos que coalham, não suportando nenhuma interpretação. Sem nada deixar ao não signo, tudo parece permanecer no nível estritamente semântico. Ele se fecha sobre si mesmo, sem se referir a um mundo extrassigno, constituindo um espaço vazio ou esvaziado, pois sua semiose (a sua significação) torna-se ilimitada. Como, por exemplo, aquilo que diz Barthes a respeito do pacote de presente: "[...] a caixa é o objeto do presente, não o que ela contém [...] de invólucro a invólucro, o significado foge" (BARTHES, OC, III, 2002, p. 387).

Ora, o termo vazio, tal qual o pensa Barthes, esse esvaziamento da linguagem não tangencia nenhuma problemática metafísica. Não é o nada, como ele mesmo confessa ao mundo, numa entrevista feita por Guy Scarpetta à revista Promesse, em 1971: “[...] o vazio não deve ser concebido (figurado) sob a forma de uma ausência (de corpos, de coisas, de sentimentos, de palavra, etc.: o nada) - aqui somos vítimas da física antiga [...] O vazio é antes o novo, o retorno do novo (que é o contrário da repetição)" (BARTHES, OC, III, 2002, p. 995).

É, entretanto, numa entrevista para L'Express de um ano antes, em 1970, que Barthes esclarece perfeitamente sua concepção de signo vazio, por meio de um exemplo simples: o dicionário. Para o semiólogo, esse objeto constitui-se como um inventário da língua composto de significantes (verbetes impressos em negrito), seguidos de sua definição, que tem valor de significado. E esses, por sua vez, também são constituídos de outras palavras, ou seja, palavras sobre palavras ao infinito. Conclui assim Barthes:

Um dicionário é um objeto perfeitamente paradoxal, vertiginoso, ao mesmo tempo estruturado e indefinido, o que faz dele um grande exemplo, pois é uma estrutura infinita descentrada, pois que a ordem alfabética em que é apresentado não implica nenhum centro (BARTHES, OC, III, 2002, p. 680).

Em O Império dos signos, ele desloca o termo vazio de sua dimensão metafísica, atribuindo-lhe sutilezas e nuances que o restringem, cerne como a fenda, quando ele fala dos olhos, "os olhos, e não o olhar, a fenda, e não a alma” (BARTHES, OC, III, 2002, 
p. 434). Ou então a leitura que faz do espelho que "[...] não capta nada. Recebe, mas não conserva [...] essa reflexão infinita é próprio vazio" (BARTHES, OC, III, 2002, p. 410).

A concepçáo barthesiana de vazio tem a ver, lendo-o desde o Oriente, com uma espécie de dupla descontinuidade. A primeira é da ordem da própria fragmentação da linguagem, essa descontinuidade entre a língua e o mundo, duas tópicas que não se encontram, que é propriamente estabelecida na primeira postulação da linguística saussuriana: o arbitrário do signo. Não há nenhuma convencionalidade no laço que une o "som" (significante) e a "representação psíquica" ou "conceito" (significado) (SAUSSURE, 1995). Não à toa, para citar Barthes em $O$ Império dos signos, no Oriente "o signo é uma fratura que jamais se abre senáo sobre o rosto de outro signo” (BARTHES, OC, III, 2002, p. 389).

Não se está, de certa maneira, distante daquilo mesmo que Barthes já havia surpreendido no artesanato de estilo flaubertiano, e que vale para toda a literatura moderna e de vanguarda: o "texto" e o "real". Uma poética pura em que a obra se afirma autônoma. No interior do próprio romance, o que se vê náo é um a realidade representada, mas a construção de uma determinada realidade. E, ao mesmo tempo, questionando os limites da língua, faz apelo ao "real", a um efeito de real, já que o "real" é aquilo que não pode ser representado, e escapando a todo discurso, ele é apenas demonstrável - "não se pode fazer coincidir uma ordem pluridimensional (o real) e uma ordem unidimensional (a linguagem)" (BARTHES, OC, V, 2002, p. 435), assinala Barthes em Aula.

A desconfiança da cristalização de um significado último e imutável produz em Barthes um desejo incansável de combate contra a tirania sígnica do sentido único. "Visivelmente, ele sonha com um mundo que fosse isento de sentido (como de serviço militar)" (BARTHES, OC, IV, 2002, p. 664), escreve Barthes em Roland Barthes por Roland Barthes. $\mathrm{O}$ vazio barthesiano, é preciso salientar, não é apenas um ataque frontal ao pleno e à "imagem de uma substância última"; consiste, na verdade, num combate a sua "má-forma”, que Barthes entrevê na repetição e no estereótipo.

Acrescente-se algumas outras linhas à essa primeira nota semiótica. Essa primeira descontinuidade (desenlace) é acrescida de 
uma "isenção" ou "evacuação" de sentido. Tomando o termo sentido como "o conteúdo (o significado) de um sistema significante" (BARTHES, OC, II, 2002, p. 450), essa isenção de sentido se dá, no plano semiótico, no não fechamento do signo num único significado. $\mathrm{O}$ significado não encontra imediatamente um estereótipo verbal em que se pode esgotar, entrando numa certa faixa enigmática da significação. Ao não se deixar reduzir à verbalidade, torna-se forçosamente enigmático - ou, para usar uma expressáo do próprio Barthes, o conteúdo (significado) torna "inteiramente traumático". O trauma é também esse "ponto zero" da suspensão do sentido que designa o vazio do signo, através da recusa de toda "solidificação' semântica”.

\section{O descontínuo e o combinatório}

Por ocasião da descoberta do sistema sígnico oriental, Barthes esbarra entáo com o signo que para o folhado infinito do sentido e vale por si mesmo. E, como se sabe, o máximo do inexplicável se encontra naquilo que é, para o semiólogo, a arte da transparência absoluta: o grau zero. Isto é uma escapada da linguagem de toda forma de servidão e de alienação plenamente revelada na sua face legível, conduzindo-a à abolição de sentido, que não quer dizer o contrário, o ilegível (o não signo; o não sentido, pois estes são retomados como sentido do não sentido), mas aquele em que o sentido é obstruído, suspendendo toda a significação. Nesse sistema barthesiano denominado o Japão, o paradigma se torna impossível, e o sintagma inexplicável.

Nesse esfacelamento do paradigma e na aberração do sintagma, entra-se na segunda descontinuidade que desejo assinalar, que é da ordem do próprio discurso, ou seja, do tecido tramado a partir dos traços delineados desse sistema chamado Japão. O tecido ou texto é todo fragmentado como o é também a tempura: fragmento de legumes e de crustáceos cristalizados na fritura,

[...] reduz-se a um pequeno bloco de vazio, a uma coleção de buracos; o alimento chega, assim, ao sonho de um paradoxo: o de um objeto puramente intersticial, ainda provocante porque esse vazio é fabricado para que nos alimentemos dele (às vezes, o alimento é construído 
em bola, como uma bolha de ar) (BARTHES, OC, III, 2002, p. 368).

Essa aeração ou fragmentação do discurso, que Barthes entrevê na tempura, melhor se evidencia quando se compara mais de perto o sistema de alimentaçáo com o sistema da língua. Lembrando da comparaçáo clássica que faz Saussure do sistema da língua como um jogo de xadrez (existem elementos que deslocam nas casas de um tabuleiro e regras para seu deslocamento), no sistema de alimentação japonês "um prato de comida é um quadro", pois é "[...] inteiramente visual (pensada, arrumada, manejada pela visão e até mesmo por uma visão do pintor, do grafista)" (BARTHES, OC, III, 2002, p. 367). Não há um significado para cada alimento, e isso permite entender como o sistema funciona. Eles não se combinam da mesma maneira que no Ocidente. Sabe-se, no Ocidente, o cardápio é rígido tanto em sua composição quanto no consumo, exemplifica Barthes, naquela mesma entrevista já mencionada para L'Express: "Basta ir a um restaurante: oferecem-se invariavelmente antepastos, entradas, assados, queijos, sobremesas segundo uma ordem inexorável. É a ordem lógico-temporal da narrativa clássica e não se pode mudar" (BARTHES, OC, III, 2002, p. 681).

Ouçamos a voz de Barthes ao rememorar o sistema alimentar Oriental:

[...] sobre a mesa, sobre a bandeja, a comida nunca é mais do que uma coleção de fragmentos, dos quais nenhum é privilegiado por uma ordem de ingestão: comer não é respeitar um cardápio (um itinerário de pratos), mas colher, com um toque ligeiro de palitos, ora uma cor, ora uma outra, ao sabor de uma espécie de inspiração que aparece, em sua lentidão, como acompanhamento desligado, indireto, da conversa (que pode ser, ela mesma silenciosa) (BARTHES, OC, III, 2002, p. 369).

No Oriente, reina a lógica da impertinência, que não se submete a uma continuidade lógica de causalidade vigente no Ocidente. Como num nouveau roman de Robbe-Grillet, os alimentos, dispersos e separados em pequenas porçóes sobre a bandeja, permitem ao sujeito 
construir de maneira livre e totalmente reversível seu próprio discurso alimentar. É o que demonstra o semiólogo no fragmento intitulado "A isenção do sentido", de $O$ império dos signos, em que o abre notando que "O Zen inteiro conduz a guerra contra a prevaricação do sentido" (BARTHES, OC, III, 2002, p. 407). E, então, conclui: “[...] a via budista é precisamente aquela do sentido obstruído: o arcano mesmo da significação, a saber o paradigma, torna-se impossivel' (BARTHES, OC, III, 2002, p. 407). Esse estilhaçar do paradigma próprio do Zen faz "aparecer a derrisão do disparador paradigmático e o caráter mecânico do sentido" (BARTHES, OC, III, 2002, p. 408). A experiência que o satori revela é "fosco da linguagem". Esse "fosco da linguagem" é o vazio do significado, e não o nada do significante.

Se o vazio, na visão barthesiana, parece cintilar em toda parte no Oriente, é porque, lendo-o como texto, ele o vê como descontínuo e combinatório, um incidente (em tudo aquilo que nele há de surpresa, de incongruência e de ruptura da coerência), já que sempre alguma coisa nesse país chamado Japão o advém.

Barthes, portanto, náo descreve seu Japáo: ele o pinta, desenha e colore segundo um método bastante livre que ele mesmo denomina de "acidente controlado", em que o acaso é de certa forma controlado, construindo pequenos quadros [tableautin] do Japão, que são postos "ao lado de" (BARTHES, OC, IV, 2002, p. 487) tantos outros desses quadrinhos que ao final, justapostos, não produzem nenhuma "mensagem" - o texto não "pega", "não quer para si"7 -, pois deles, pelo processo de "recorte aleatório" mesmo, não resta nenhum tecido contínuo de narratividade, mas simplesmente, interstícios, acúmulos decomeços, intervalos.

A revelação de uma escritura em fragmento pelo texto Japão, para Barthes, quebra a possibilidade de metalinguagem. Está-se diante de um vazio semântico provocado pela dinâmica das variaçôes, em que a forma importa mais do que o conteúdo, e por sua vez "o conteúdo importa menos do que sua translação” (BARTHES, 2002, p. 35).

7 Vouloir-saisiré é traduzido no Brasil ora por não querer-agarrar, ora por não querer-possuir. Opto pela tradução proposta por Isabel de Pascoal, na edição portuguesa, de Fragmentos de um discurso amoroso: não querer-para-si. 
Se de acúmulos de início se faz o texto Japão, e se eles em si mesmos são como pequenos quadros, isso permite passar a esse curto poema japonês, o haikai, cuja forma breve encantou Barthes. Mas não é apenas pelo plano da forma que ocorre o encantamento barthesiano por esse poema. É, sobretudo, o signo funcionando em sua pura designação referencial. Não ocorre aí nenhuma descrição. A arte do haikai é contradescritiva. É a pura arte da "impressão", "[...] na medida em que todo estado da coisa é imediatamente, obstinadamente, vitoriosamente convertido numa essência frágil de aparição" (BARTHES, OC, III, 2002, p. 405).

O haikai é, aliás, um dos verbetes mapeados por Jean-Pierre Richard em seu Roland Barthes sans paysage. Ao dedicar a ele toda uma seção de seu livro, Richard nota que esse encantamento de Barthes por essa forma poética nasce da interrupção típica desse poema, que para o crítico não é senão uma espécie de "protesto de vazio" (RICHARD, 2006, p. 50-51), cujo correlato formal é o salto sintático, já que de uma linha par à outra o narrador passa sempre uma outra coisa. Essa interrupção é mais notável neste exemplo de haikai do poeta Coyaud Kusatao, "Seres sem memória/ Neve fresca/ Esquilos saltitantes". A esses versos Barthes dirige a seguinte análise: "ligação instantânea (e, no entanto, separada: nenhuma lógica) entre aquele que é sem memória e a neve" (BARTHES, 2003, p. 121).

Trata-se de momentos de fragilidade profunda, pequenos nadas em que o significado se evapora, restando apenas um tênue significante. O signo oriental é mais uma apresentação do que uma representação. Contrariamente a toda arte Ocidental - que, manifestando todo seu discurso sobre a forma de descrição, se esforça para ser mimesis a fim de que o mundo representado soe real -, no Oriente “[...] a própria estrutura do japonês restabelece ou retém esses seres [personagens fictícios de uma história] em qualidade de produtos, de signos separados do álibi referencial por excelência: o da coisa viva” (BARTHES, OC, III, 2002, p. 354). Barthes percebe claramente isso no teatro do Bunraku, que recusa “'animar' um objeto inanimado" e, por isso mesmo, "[...] dispensa o conceito que se esconde por detrás de toda animação da matéria, e que é simplesmente 'a alma”" (BARTHES, OC, III, 2002, p. 398). 
Esse caráter de pura designação do signo Oriental pode ser entrevisto ainda naquilo que diz Barthes do autor japonês interpretando o papel de uma mulher: "[...] o autor oriental não busca mais do que combinar os signos da Mulher [...] esses signos purificam o corpo de toda expressividade: podemos dizer que, pelo fato de serem signos extenuam o sentido" (BARTHES, OC, III, 2002, p. 419) do rosto do travesti, pois para ele o disfarce não imita, não se funda numa mimesis, uma vez que "O travesti oriental não copia a Mulher, ele a significa $[. . .$.$] a Feminilidade é dada à leitura, não à visão" (BAR-$ THES, OC, III, 2002, p. 393).

\section{Estética do vazio}

A noção de "vazio de fala" - que se buscou fazer reavivar em cada objeto alvo da leitura binária barthesiana (Ocidente/Oriente) -, inserido na trama conceitual barthesiana em $O$ Império dos signos, de par com conceito de "grau zero", vem ressinalizar que toda arte só pode se fundar visando a uma "moral da forma", que aja sobre a raiz mesma do sentido, disfuncionalizando a linguagem.

Tudo isso leva a uma definiçáo zen da arte. Toda arte aparece, aos olhos de Barthes, como uma imensa prática destinada a abolir ou a romper com o infinito ciclo vicioso da linguagem, e, portanto, a silenciar, obstruir a significação em detrimento de um esvaziamento da máquina da linguagem. Noutros termos, nessa concepção, a arte detém-se a um "não dizer", a um quase se desdizendo ou a um dizer muito pouco, cujo arranjo dos signos não envereda nem pelo patético nem pelo pastiche.

A obra barthesiana alude a um projeto estético de "despersonalização" (do signo vazio, do sujeito vazio, do sentido vazio), logo percebida pela crítica, escritora e uma das leitoras americana mais notórias de Barthes, Susan Sontag em L'ecriture même: à propos de Barthes, e por ela batizado como uma "estética da ausência" (SONTAG, 2009, p. 62). Talvez o projeto estético de Barthes não cruze necessariamente com uma concepção de "ausência", como quer fazer entender Sontag.

Revendo Barthes desde $O$ Neutro - até porque é em direção dessa noção que tudo parece convergir em seu pensamento -, sua 
concepção estética não consiste, como quer fazer acreditar Sontag, numa espécie de anulação, num apagamento, mas numa posição ou presença que se póe fora do paradigma. Lê-se no volume que reúne as páginas manuscritas do curso "O Neutro", o seguinte: "Defino o Neutro como aquilo que destrama o paradigma, ou melhor, chamo Neutro tudo o que destrama o paradigma" (BARTHES, 2002, p. 31). Com essa definição de Barthes para o seu Neutro, não se está tão distante da noção mesma de zen, que é "[...] um estado de mente onde a tensão dos opostos é reduzido ao silêncio, não tendo sido aniquilada nem exorcizada, negada ou ignorada, mas apenas abandonada" (WATTS, 1960, p. 87). Esse abandono, a meu ver, faz de certa maneira cintilar o Neutro barthesiano, pois se refere à "suspensão", ao estado de pensamento em que náo se nega nem se afirma nada.

Por isso mesmo, O Neutro de Barthes não pode ser compreendido sob a forma negativa. Ele, na verdade, faz apelo a uma estética da literalidade. Uma outra maneira de entrever esse "literal possível" encontra-se nas folhas do projeto Vita Nova, em que se vê ou se lê "formas (narrativa, descrição, fragmentos, falsos diálogos), mas não 'conteúdo'" (MARTY, 2002, p. 21), como assinala Éric Marty em sua apresentação ao tomo V das Oeuvres Complètes. É ao mesmo tempo também, ao menos a leitura do curso nos faz acreditar nisso, um gosto pelo signo naquilo que ele tem de mais puro.

De resto, o destramar do paradigma suscitado pelo Neutro não quer absolutamente apontar nem sugerir um apagamento ou uma abertura a uma ausência. Mesmo que isso possa ter a forma de uma ausência, consiste numa espécie de apelo a uma forma, a uma forma ideal de ausência; à forma mais literal possível que corresponde à concepção mesma de vazio em Barthes. Por isso mesmo, o nome mais justo a lhe atribuir seria talvez "estética do vazio", com tudo que o termo vazio guarda, em Barthes, de neutralidade, de "silêncio" ou rebaixamento da voz que faz "inexprimir o exprimível” (BARTHES, OC, II, 2002, p. 279), e não de afastamento (desengajamento). Esse gesto de suspensão da linguagem é denominado por Jean-Pierre Richard de "o grau zero da presença" (RICHARD, 2006, p. 17).

A estética amparada na ética do signo vazio de Barthes reivindica um rebaixamento da sublimidade. Uma acepção de sublime não romântica. Como se sabe, o sublime consiste, por definição, num 
elevado, num "exagero emocional do momento sublime" que "[...] sustenta uma ilusão, uma união metafórica com o criador, que suprime a inferioridade de nossa condição de meros ouvintes" (WEISKEL, 1995, p. 18). E essa elevaçáo provém dos altos efeitos de sentido e do mais forte efeito de estilo. A estética de Barthes, entretanto, pede para ser lida com uma sublimidade mística que se desdobra num esvaziamento típico da filosofia zen budista.

Retomando, por fim, o poeta Francis Ponge, evocado logo na abertura deste ensaio, a concepção de estética proposta por Barthes vai ao encontro de seu minimalismo poético, cuja neutralidade fremente escapou ao crítico-semiólogo. O conjunto de fragmentos que o poeta insiste em fazer passar por poemas e o caráter mais de "nota" (muito próxima da ideia de haikai) que essa poesia recebe clamam contra a mentira da profundidade e o "coração" romântico das coisas, isto é, contra o que chama de "lavagem cerebral idealista e cristâ" (PONGE, 1967, p. 185). Toda crítica pongiana vai na direçâo de notar que "O homem cansado de ser um espírito a convencer, e um coraçáo a comover, concebeu-se, finalmente, um dia como o que é: algo de mais material e de mais opaco, de mais ligado ao mundo, de mais pesado para carregar" (PONGE, 1967, p. 185).

\section{Referências bibliográficas}

BARTHES, Roland. Oeuvres Complètes. 5T. Nouvelle édition revue, corrigé e présentée par Éric Marty. Paris: Seuil, 2002.

. Album. Inédits, correspondances et varia. Paris: Seuil, 2015. [Éditions établi et présentée par Éric Marty. Avec L'aide de Claude Coste pour "Sur sept phrases de Bouvard et Pécuchet"].

. Le Neutre. Paris: Seuil, 2002.

. La Préparation du romance. Paris: Seuil, 2003.

CALVET, Louis-Jean. Roland Barthes - une biographie. Paris: Flammarion, 1990.

COMMENT, Bernard. Roland Barthes vers Le Neutre. Paris: Christian Bourgois, 2002.

CULLER, Jonathan. As ideias de Barthes. Tradução de Adail Sobral. São Paulo: Cultrix, 1988. 
KRISTEVA, Julia. La Révolution du langage poétique. Paris: Seuil, 1974.

MARTY, Eric. Présentation. In: BARTHES, Roland. Oeuvres Complètes, V. Paris: Seuil, 2002.

PINO, Claudia Amigo Pino. Roland Barthes: a aventura do romance. Rio de Janeiro: 7 Letras/FAPESP, 2015.

PONGE, Francis. Le Grand Recueil/Méthodes. Paris: Gallimard, 1961. . Le parti pris des choses: suivi des proêmes. Paris: Gallimard, 1967.

RICHARD, Jean-Pierre. Roland Barthes, dernier paysage. Paris: Verdier, 2006.

SAMOYAULT, Thyphaine. Roland Barthes. Paris: Seuil, 2015.

SAUSSURE, Ferdinand. Cours de Linguistique Général. Paris: Payot, 1995.

SONTAG, Susan. L'écriture même: à propos de Barthes. Oeuves Complètes, II. Paris: Christian Bourgois, 2009.

WATTS, Alan. Le Zen Bouddhisme. Paris: Seuil, 1960.

WEISKEL, Thomas. O Sublime Romântico. Rio de Janeiro: Imago, 1995.

Rodrigo Fontanari é Mestre e Doutor pelo Programa de Pós-Graduaçáo em Comunicação e Semiótica da Pontifícia Universidade Católica de São Paulo (PUC/ SP). Fez pós-doutorado no Programa de Pós-Graduação em Multimeios da Universidade Estadual de Campinas (UNICAMP). Pesquisador associado ao Résean International Roland Barthes. E-mail: rodrigo.fontanari@prof.uniso.br

Recebido em: 16/01/2018

Aceito em: 15/07/2018 